Int. J. Electrochem. Sci., 15 (2020) 2883 - 2893

International Journal of

ELECTROCHEMICAL

SCIENCE

www.electrochemsci.org

\title{
Study on Mechanical Properties of Metakaolin-Based Concretes and Corrosion of Carbon Steel Reinforcement in 3.5\% NaCl
}

\author{
Jian Zhang, Jin Yang ${ }^{*}$ Zhuoxuan Ying \\ Jiyang College, Zhejiang Agricultural and Forestry University, Zhuji 311800, China \\ *E-mail: JinYang_jyc@163.com \\ doi: $10.20964 / 2020.04 .25$
}

Received: 30 November 2019 / Accepted: 23 January 2020 / Published: 10 March 2020

\begin{abstract}
One of the techniques to improve the concrete durability is to use cement materials blended with silica fume, slag and fly ash. The use of calcined clay cement in the metakaolin form as a pozzolan for mortar and concrete has received remarkable interest in recent years. Here, in this study, corrosion behavior and mechanical property of carbon steel rebar in metakaolin cement-based concretes were investigated. To evaluate the effect of high-reactivity metakaolin in the corrosion resistance of the ordinary Portland cement (OPC) concrete, $5 \mathrm{wt} \%, 10 \mathrm{wt} \%, 15 \mathrm{wt} \%$ and $20 \mathrm{wt} \%$ metakaolin replacement levels were done in concrete production. Corrosion rate, electrochemical mass loss, compressive strength, tensile strengths, open circuit potential, and electrochemical impedance spectroscopy (EIS) of the samples were studied and discussed. The electrochemical mass loss of concrete samples revealed that $15 \mathrm{wt} \%$ metakaolin sample had smaller mass losses which exhibited an improvement in anticorrosive properties that had led to better corrosion behavior of the carbon steel rebar. The mechanical results of concrete samples indicated a gradually increase in compressive and tensile strengths with the increase in the cement blended with metakaolin. Furthermore, the EIS findings showed that $15 \mathrm{wt} \%$ metakaolin sample indicated a higher value of passive film resistance compared to other samples, indicating that more enhancement of corrosion resistance on the surface of the carbon steel rebar. Scanning electron microscopy images revealed that the concrete structure containing $15 \mathrm{wt} \%$ metakaolin was denser and more uniform than that of the OPC sample which was in accordance with studies reported by other researchers.
\end{abstract}

Keywords: Reinforced concrete; Metakaolin; Electrochemical impedance spectroscopy; Corrosion resistance; Mechanical properties

\section{$\underline{\text { FULL TEXT }}$}

(C) 2020 The Authors. Published by ESG (www.electrochemsci.org). This article is an open access article distributed under the terms and conditions of the Creative Commons Attribution license (http://creativecommons.org/licenses/by/4.0/). 